\title{
Laser-Induced Breakdown Spectroscopy Associated with Multivariate Analysis Applied to Discriminate Fertilizers of Different...
}

Article in Journal of Applied Spectroscopy · November 2017

DOI: $10.1007 /$ s10812-017-0566-4

CITATIONS

0

7 authors, including:

\section{Giorgio S Senesi}

Italian National Research Council

71 PUBLICATIONS 1,335 CITATIONS

SEE PROFILE

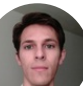

\section{Paulino Ribeiro Villas Boas}

Brazilian Agricultural Research Corporation (...

45 PUBLICATIONS 1,761 CITATIONS

SEE PROFILE

\section{READS}

36

\section{Gustavo Nicolodelli}

Brazilian Agricultural Research Corporation (... 46 PUBLICATIONS 185 CITATIONS

SEE PROFILE

\section{Debora Marcondes Bastos Pereira Milori}

Brazilian Agricultural Research Corporation (...

140 PUBLICATIONS 1,537 CITATIONS

SEE PROFILE

Some of the authors of this publication are also working on these related projects: spectroscopic techniques View project 


\title{
LASER-INDUCED BREAKDOWN SPECTROSCOPY ASSOCIATED WITH MULTIVARIATE ANALYSIS APPLIED TO DISCRIMINATE FERTILIZERS OF DIFFERENT NATURE
}

\author{
G. S. Senesi, ${ }^{a^{*}}$ R. A. Romano, ${ }^{b}$ B. S. Marangoni, ${ }^{c}$ G. Nicolodelli, ${ }^{d}$ \\ P. R. Villas-Boas, ${ }^{\text {d V. M. Benites, }}{ }^{\mathrm{e}}$ and D. M. B. P. Milori ${ }^{\mathrm{d}}$
}

UDC 543.423:631.8

A number of phosphate rocks and organomineral P fertilizers was analyzed comparatively by laser-induced breakdown spectroscopy (LIBS) in both single- and double-pulse modes associated with two chemometric methods, i.e., principal components analysis (PCA) and partial least squares regression (PLSR). PCA was demonstrated to be a valuable method for the identification of spectral differences between similar samples with only minor compositional differences. The raw and normalized LIBS spectra were able to provide effective identification and discrimination at a 95\% confidence level and in good agreement with the reference concentrations. Results obtained confirm the promising potential of LIBS for the rapid classification of $P$ fertilizers in situ.

Keywords: laser-induced breakdown spectroscopy, phosphate rocks, organomineral fertilizers, principal components analysis, partial least squares regression.

Introduction. Optimal fertilizer management is instrumental in obtaining optimized plant productivity and quality by avoiding excessive use that may lead to severe environmental damage such as contamination of surface water and groundwater, especially in areas of intensive crop production, whereas nonoptimal use may cause reduced crop yields. In general, a mineral/inorganic fertilizer is required to guarantee an optimal input of the major nutrients $\mathrm{N}, \mathrm{P}$, and $\mathrm{K}$ into soil. In contrast, an organomineral fertilizer consists of an appropriate mixture of a mineral rock or an inorganic fertilizer and an organic material generally derived from natural sources such as plant and animal by-products, sewage sludges, municipal biosolid wastes, seaweeds, etc., which can provide a certain amount of major nutrients and organic matter to the soil.

In particular, to save the limited primary P reserves available worldwide [1], the use of new P fertilizers consisting of mixtures of organic and secondary mineral $\mathrm{P}$ sources available on the market represents a promising alternative. However, correct and efficient use of organomineral P fertilizers of new generation, i.e., mixtures of phosphate rocks and treated organic wastes, feature a variable composition that requires the development of analytical techniques able to measure and discriminate accurately, rapidly, and cheaply the P content. This will improve their management and efficiency in agriculture.

Laser-induced breakdown spectroscopy (LIBS) is an emerging, rapidly developing and promising analytical technique that can provide real-time, cheap, fast, and easy-to-use multielemental analysis of a variety of materials [2]. LIBS is a minimally destructive method requiring little or no sample pretreatment and no chemicals and produces no disposables. Further, relatively simple, low-cost, compact, and portable instrument configurations and packages are available for use outside the laboratory, i.e., on site. Another advantage of LIBS is its suitability for a broad range of multivariate chemometric approaches for data analysis. In the last decades, this technique has been applied in several fields [2], including agriculture, e.g., soil, plant, and compost analyses [3-10], but only in the last years has attention been focused on fertilizer analysis [11-16].

The objectives of this work were to evaluate the performance of two LIBS systems associated with two chemometric methods, i.e., principal components analysis (PCA) and partial least squares regression (PLSR), in analyzing comparatively

*To whom correspondence should be addressed.

${ }^{a}$ CNR-Istituto di Nanotecnologia (NANOTEC)-PlasMiLab, Via Amendola 122/D, 70126, Bari, Italy; email: giorgio.senesi@nanotec.cnr.it; ${ }^{\mathrm{b}}$ São Carlos Institute of Physics, University of São Paulo, São Carlos, SP, Brazil; ${ }^{\mathrm{c}}$ Physics Institute, Federal University of Mato Grosso do Sul, Campo Grande, MS, Brazil; ${ }^{d}$ Embrapa Agricultural Instrumentation, São Carlos, SP, Brazil; ${ }^{e}$ Embrapa Solos, Rua Jardim Botanico, Rio de Janeiro, RJ, Brazil. Abstract of article is published in Zhurnal Prikladnoi Spektroskopii, Vol. 84, No. 5, p. 839, September-October, 2017. 
TABLE 1. Major Elemental Composition of Phosphate Rocks and Organomineral Fertilizer Samples Examined in This Work

\begin{tabular}{|c|c|c|c|c|c|c|c|c|c|c|}
\hline $\begin{array}{l}\text { Sample Source and Mixture } \\
\text { Composition }\end{array}$ & $\begin{array}{c}\mathrm{P} \\
(\mathrm{wt} . \%)\end{array}$ & $\begin{array}{c}\mathrm{Ca} \\
(\mathrm{wt} . \%)\end{array}$ & $\begin{array}{c}\mathrm{Fe} \\
\text { (wt.\%) }\end{array}$ & $\begin{array}{c}\mathrm{Al} \\
\text { (wt.\%) }\end{array}$ & $\begin{array}{c}\mathrm{Mg} \\
\text { (wt.\%) }\end{array}$ & $\begin{array}{c}\mathrm{K} \\
(\mathrm{wt} . \%)\end{array}$ & $\begin{array}{c}\mathrm{Na} \\
\text { (wt.\%) }\end{array}$ & $\begin{array}{c}\mathrm{C} \\
(\mathrm{wt} . \%)\end{array}$ & $\begin{array}{c}\mathrm{N} \\
(\mathrm{wt} . \%)\end{array}$ & $\begin{array}{c}\mathrm{H} \\
(\mathrm{wt} . \%)\end{array}$ \\
\hline \multicolumn{11}{|c|}{ Group A } \\
\hline $\mathrm{PR}^{\mathrm{a}}-$ Arad, Israel & 26.3 & 32.1 & 0.6 & 0.53 & 1.1 & 2.0 & 5.9 & 1.4 & 0.1 & 0.4 \\
\hline $\mathrm{PR}^{\mathrm{a}}$ - Arraias, Brasil & 18.0 & 23.3 & 13.3 & 17.2 & 2.6 & 5.6 & - & 0.2 & - & 0.2 \\
\hline $\mathrm{PR}^{\mathrm{a}}$ - Bayovár, Peru & 23.4 & 24.7 & 5.1 & 4.5 & 3.0 & 2.5 & 14.4 & 1.8 & 0.3 & 0.6 \\
\hline $\mathrm{PR}^{\mathrm{a}}$ - Djabel, Algeria & 21.5 & 29.0 & 2.2 & 2.5 & 11.2 & 1.4 & 9.7 & 2.1 & 0.1 & 0.4 \\
\hline $\mathrm{PR}^{\mathrm{a}}$ - Gafsa, Tunisia & 23.3 & 29.6 & 1.8 & 2.7 & 3.2 & 0.9 & 11.6 & 1.9 & 0.1 & 0.4 \\
\hline \multicolumn{11}{|c|}{ Group B } \\
\hline $\mathrm{NCPL}^{\mathrm{b} \#}+\mathrm{PR}$ Arraias & 11.7 & 15.2 & 5.5 & 14.5 & 3.7 & 10.6 & 8.0 & 15.1 & 1.7 & 1.8 \\
\hline $\mathrm{CPL}^{\mathrm{c} \#}+\mathrm{PR}$ Arraias & 11.5 & 20.2 & 12.9 & 8.6 & 5.2 & 17.1 & 8.6 & 13.9 & 1.1 & 1.8 \\
\hline $\mathrm{NCPL}^{\mathrm{b} \#}+$ PR Bayovár(2010) & 12.4 & 17.2 & 11.0 & 7.7 & 5.1 & 17.6 & 8.0 & 17.8 & 1.4 & 2.1 \\
\hline $\mathrm{NCPL}^{\mathrm{b} \#}+$ PR Bayovár(2013) & 6.7 & 15.0 & 10.2 & 8.3 & 3.9 & 11.8 & 2.5 & 18.7 & 1.9 & 1.8 \\
\hline $\mathrm{CPL}^{\mathrm{c} \#}+$ PR Bayovár(2013) ${ }^{*}$ & 7.8 & 11.8 & 16.2 & 4.9 & 5.8 & 16.6 & 3.3 & 13.6 & 1.0 & 2.0 \\
\hline \multicolumn{11}{|c|}{ Group C } \\
\hline $\mathrm{NCPL}^{\mathrm{b} \Delta}+\mathrm{MAP}^{\mathrm{d}}(2010)^{*}$ & 12.1 & 4.1 & 5.0 & 3.8 & 3.8 & 69.6 & 3.3 & 16.8 & 3.0 & 2.1 \\
\hline $\mathrm{CPL}^{\mathrm{c} \Delta}+\operatorname{MAP}(2010)^{*}$ & 20.1 & 5.0 & 8.0 & 4.3 & 3.8 & 22.2 & 3.1 & 10.6 & 4.6 & 2.0 \\
\hline $\mathrm{NCPL}^{\mathrm{b} \Delta}+\operatorname{MAP}(2011)^{*}$ & 17.0 & 1.8 & 5.9 & 4.6 & 3.2 & 15.3 & 3.3 & 15.8 & 5.1 & 2.1 \\
\hline $\mathrm{NCPL}^{\mathrm{b} \Delta}+\mathrm{MAP}(2013)^{*}$ & 18.3 & 3.2 & 10.4 & 7.2 & 3.3 & 14.2 & 2.9 & 9.7 & 4.5 & 2.1 \\
\hline $\mathrm{CPL}^{\mathrm{c} \Delta}+\operatorname{MAP}(2013)^{*}$ & 20.1 & 4.0 & 10.3 & 2.8 & 4.6 & 18.0 & 3.6 & 12.3 & 4.4 & 2.1 \\
\hline
\end{tabular}

${ }^{\text {a }}$ Phosphate rock.

${ }^{\mathrm{b}}$ Noncomposted poultry litter.

${ }^{\mathrm{c}}$ Composted poultry litter.

${ }^{\mathrm{d}}$ Monoammonium phosphate.

* Year of production.

${ }^{\#}$ Mixture at a ratio of 1:1 (in wt.\%).

${ }^{\Delta}$ Mixture at a ratio of 2:1 (in wt.\%) + bentonite $2 \%$.

a suite of five phosphate rocks and ten organomineral fertilizers of different composition and sources. In particular, the performance of PCA and PLSR was evaluated in resolving and extracting information from the whole LIBS spectra acquired from the samples examined, thus allowing their identification, discrimination, and classification. The Student's $t$-test was also applied to the whole LIBS spectra to evaluate the most relevant spectral emission lines that influence the classification of samples examined and to quantify the level of significance of differences between the classes. Further, a cross-validation procedure was applied to PLSR results to ensure that the classification algorithm was robust also for unseen data.

Materials and Methods. Samples. Three groups of samples were used in this work (Table 1), which include: (a) five phosphate rocks (PR) of different sources and composition (group A); (b) five organomineral fertilizers consisting of mechanically homogenized mixtures of a PR and either a noncomposted poultry litter (NCPL) or a poultry litter composted (CPL) together with sugarcane bagasse for about 120 days in static piles at 1:1 ratio (wt.\%) (group B); and (c) five organomineral fertilizers consisting of mechanically homogenized mixtures of either NCPL or CPL and monoammonium phosphate (MAP) at a 2:1 ratio (wt.\%) with 2\% of bentonite (B) as additive. All organomineral fertilizers were prepared in the Embrapa laboratories. To ensure homogeneity, before mixing and granulating, each component was ground using a micronex kinetic disintegration system (KDS), and the particles obtained were sieved through a $0.5-\mathrm{mm}$ sieve. Samples were then dried to less than $10 \%$ moisture and stored in sealed bottles in ambient temperature. For LIBS analyses, two pellets of each sample were prepared by applying a pressure of $6 \times 10^{8} \mathrm{~N} / \mathrm{m}^{2}$ for $30 \mathrm{~s}$. 
LIBS experiment. Two LIBS instruments were used in this work. In particular, a commercial LIBS 2500 spectrometer (Ocean Optics) consisting of a Nd:YAG Q-Switch laser system (Quantel, Big Sky Laser Ultra50) operating at the wavelength of $1064 \mathrm{~nm}$ (IR) with a maximum energy of $60 \mathrm{~mJ}$, a repetition rate of $10 \mathrm{~Hz}$, and a pulse width of $8 \mathrm{~ns}$, was used for the acquisition of raw single-pulse (SP) spectra. The integration time was fixed at $2.1 \mathrm{~ms}$ with a delay time of $2.5 \mu$ s for all measurements. The sample holder was manually moved to avoid pulse accumulation in the same spot. The diameter of the laser spot on the sample was about $100 \mu \mathrm{m}$. A set of a fiber optic bundle was used to collect the light from the plasma and deliver it to seven spectrometers, each of which consisted of a 2048-pixel charge-couple device (CCD) array. The distance between the sample and the optical fiber bundle was approximately $7 \mathrm{~mm}$. The spectra acquisition ranged from 189 to $966 \mathrm{~nm}$ with $0.1 \mathrm{~nm}$ optical resolution. Raw LIBS spectra were then normalized by dividing the whole broadband spectra by the area under the entire spectral range acquired. Spectrum normalization allowed us to eliminate any background emission interference and avoid any possible disturbance effect in samples classification. Finally, two sets of SP LIBS spectra, i.e., raw and normalized ones, were obtained at the wavelength of $1064 \mathrm{~nm}$ (IR) by the commercial instrument.

The benchtop LIBS instrument was used in two different modes, i.e., single-pulse (SP) and double-pulse (DP) modes. Spectra were acquired at the wavelength of $532 \mathrm{~nm}$ (VIS), whereas the acquisition of DP spectra was performed using two laser beams in collinear geometry, the first at the wavelength of $532 \mathrm{~nm}$ (VIS) and the second at $1064 \mathrm{~nm}$ (IR). The VIS laser pulse was generated by a Nd:YAG Q-Switch laser (Brilliant, Quantel) with a maximum energy of $180 \mathrm{~mJ}$ and $4 \mathrm{~ns}$ width, whereas the IR laser pulse was generated by a Nd:YAG Q-switch laser (Ultra, Quantel) with a maximum energy of $75 \mathrm{~mJ}$ and $6 \mathrm{~ns}$ width. The detection was performed by a 400-Butterfly Arielle system operating in the range of $275-750 \mathrm{~nm}$ with a spectral resolution of 29-80 pm. An intensified (I) CCD camera of $1024 \times 1024$ pixels was used to record the spectra with a $400 \mathrm{~ms}$ integration window. The interpulse and measurement delays were set at $500 \mathrm{~ns}$, and the width gate at $10 \mu \mathrm{s}$. The laser beams were guided using appropriately coated lenses, and a fiber optical system was used to collect the light from the plasma. A delay generator (Quantum Composers) was used to synchronize the laser beams and the acquisition system. A personal computer was used for the control of the delay generator and data storage. Two sets of spectra were finally obtained and studied by the benchtop instrument, i.e., SP spectra at $532 \mathrm{~nm}$ (VIS) and DP spectra at 532 and $1064 \mathrm{~nm}$ in succession.

All the measurements were carried out in atmospheric air at ambient pressure. Fifty spectra were obtained in different positions of each pellet. Each spectrum was the result of five accumulated laser shots, preceded by one cleaning shot.

Phosphorus, metal elements, and CHN reference analyses. The total P contents (Table 1) were measured by an inductively coupled plasma optical emission spectrometer (ICP-OES) (OPTIMA 3000) in radial view configuration in digests obtained by boiling $1 \mathrm{~g}$ sample in $20 \mathrm{~mL} \mathrm{HNO}_{3}$ and $5 \mathrm{~mL} \mathrm{HCl}$. The total contents of metal elements, including $\mathrm{Ca}$ and $\mathrm{Fe}$ (Table 1), were measured by an ICP-OES (VISTA PROCD, Varian) in radial view configuration in digests obtained by heating at $110-120^{\circ} \mathrm{C} 1 \mathrm{~g}$ sample in $20 \mathrm{~mL}$ of nitric acid.

The total C, H, and N contents (Table 1) were measured by a Perkin-Elmer $2400 \mathrm{CHNS} / \mathrm{O}$ analyzer series II on samples ground into particles smaller than $0.15 \mathrm{~mm}$. The samples were weighed directly in consumable tin capsules using a microbalance (Perkin-ElmerAD-6 Auto Balance Controller) that was connected to the $2400 \mathrm{CHNS} / \mathrm{O}$. All results of elemental analysis were calculated with reference to the known $\mathrm{C}$ value of the standard acetanilide by using the $K$ value factor calculation.

Chemometric methods. Two chemometric methods commonly used in LIBS analysis, i.e., PCA and PLSR [17-19], were applied in this study. First, all data, i.e., all emission lines (individual pixels from a MALDI image), contained in each of the four sets of LIBS spectra obtained by the four different approaches used were processed by PCA. Then, a successive PCA analysis was performed considering only the data in LIBS spectra of clusters that could be separated further. In particular, the PCA procedure can convert a spectrum with $n$ peaks in an $n$-dimensional space plot, i.e., transform the original coordinate system in new coordinates called principal components (PCs) of various variance. In particular, the first PC points in the direction of the highest variance, the second PC points in the direction of the second highest variance, and so on. PCA analysis is thus able to extract the LIBS spectrum in the form of linear combinations of variables and evaluate how much variance in the dataset is explained by each PC. By this procedure the most relevant PCs that retain most of the original total variance can be identified, and the PCs that contribute little to the variance can be removed. Thus PCA is a tool able to reduce multidimensional data to a lower dimension while retaining most of the information, thus making data analysis more manageable and straightforward. The values that the spectra have in the PC-coordinate system are called scores; thus the coordinates calculated along the PCs (scores) can be used to evaluate similarities and/or differences between the spectra. Finally, the samples can be grouped into appropriate classes by analyzing the scores and PCs together.

The multivariate linear method PLSR is used when the number of prediction variables is much greater than the number of observations. The method consists in determining a new set of variables whose variation is maximized to explain 


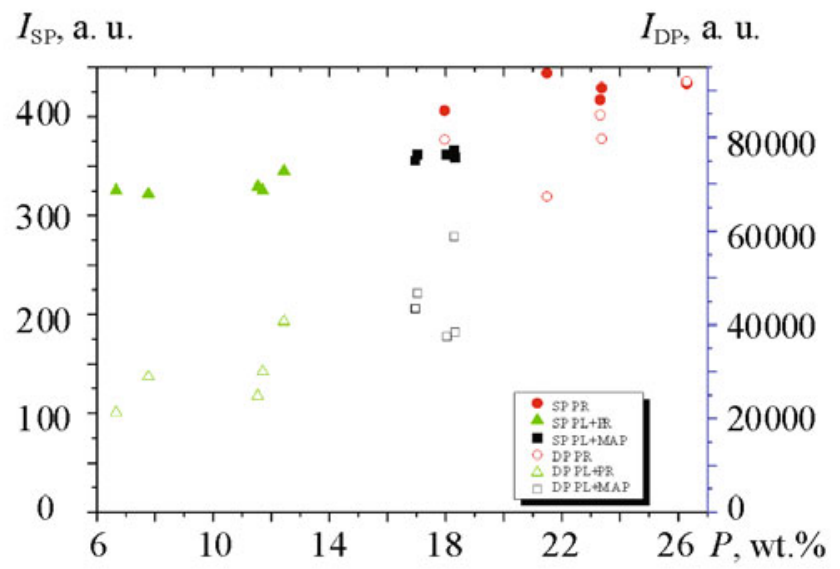

Fig. 1. Relative emission line intensities obtained by SP and DP LIBS-ICCD for the $\mathrm{P}$ peak at $213.62 \mathrm{~nm}$ vs. P concentrations obtained by ICP-OES.

the response variables [20]. The model accuracy is determined by performing a cross-validation leave-one-out test that consists in leaving one sample out of the calibration model and testing the remaining samples in the model, then repeating the test procedure for each of the other samples.

The Student's $t$-test, which is based on statistical concepts like probability, variance, and distribution, is also used as a suitable approach to differentiate between the two groups of samples when the distribution of a variable, i.e., the correlation coefficient and problem coordinate, is close to normal. This test can thus indicate whether two normally distributed populations are statistically significantly different [21]. If the $p$ value of the test results is less than the significance level chosen, i.e., 0.05 , the sample result is different at a $95 \%$ confidence level.

Results and Discussion. The atomic emission lines of interest measured by SP LIBS-CCD in all samples examined were those of $\mathrm{P}$ (at 213.62 and $214.91 \mathrm{~nm}$ ), Ca (at $422.67 \mathrm{~nm}$ ), and $\mathrm{Fe}$ (at 370.56 and $373.83 \mathrm{~nm}$ ). To discover and quantify which spectral emission lines influence sample classification significantly, two Student's $t$-tests were performed in each point of the spectra, the one considering PR and PL + MAP fertilizers and the other PR and PL + PR fertilizers. A confidence level of $95 \%(p>0.05)$ was assumed to indicate that the emission lines considered were significant to differentiate the two classes of fertilizers, whereas a $p<0.05$ meant that the emission lines considered were not significant for this purpose. Good correlations were found between the relative spectral line intensity obtained both by SP and DP LIBS-ICCD for P, Ca, and Fe and the corresponding average concentration of these elements measured by ICP-OES for the three classes of samples. In particular, Fig. 1 shows the correlations found for the P peak at $213.62 \mathrm{~nm}$.

The PCA analysis of SP LIBS broadband spectra acquired over the range 186-966 nm by the commercial LIBS-CCD system was performed using two approaches, the one based on raw spectra and the other on normalized spectra. The PCA procedure applied to raw spectra (Fig. 2) allowed us to discern similarities and differences in the given set of data and classify the samples examined into two well differentiated clusters, i.e., phosphate rocks and organomineral fertilizers, on the basis of only two PCs, PC-1, and PC-2, which retain $>95 \%$ of the original total variance of their corresponding LIBS spectra. The same PCA procedure applied to normalized spectra yielded a similar sample classification. This result indicated that even the raw broadband SP LIBS spectra without any normalization of spectral data can provide valuable data for distinguishing the samples. A more detailed PCA analysis of LIBS data of only organomineral fertilizers, which include PL + PR and $\mathrm{PL}+\mathrm{MAP}$ samples, allowed us to further distinguish two different clusters of different composition on the basis of the same two PCs, PC-1, and PC-2, which retain $>95 \%$ of the original total variance of their corresponding LIBS spectra.

The results obtained by the commercial SP LIBS-CCD system were confirmed by PCA analysis of the SP and DP LIBS broadband spectra acquired by the benchtop LIBS-ICCD system over the range from $275-750 \mathrm{~nm}$. Also in this case two PCs were able to capture $>95 \%$ of total variance, and all samples could be grouped into two clusters based on the variance of their corresponding LIBS spectra. Similar to SP LIBS-CCD spectra, a further PCA analysis of SP and DP LIBS broadband spectra of only organomineral fertilizers allowed us to distinguish two different clusters, PL + PR and PL + MAP, using only the two PCs able to retain $>95 \%$ of the total variance. 


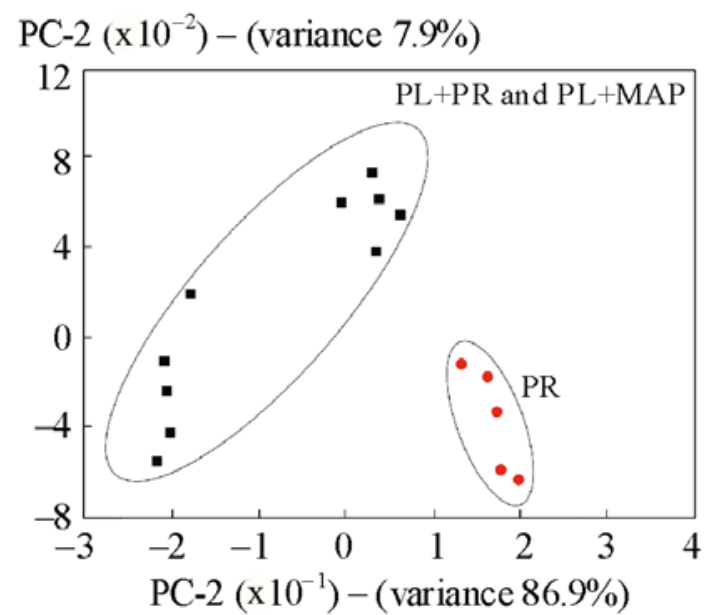

Fig. 2. 2D score plots of all samples, i.e., phosphate rocks (PR), poultry litter (PL) + phosphate rocks (PR), and poultry litter (PL) + monoammonium phosphate (MAP) grouped into classes on the basis of PCA analysis of raw broadband spectra acquired by the commercial SP LIBS-CCD instrument.

TABLE 2. Probability Distribution of Raw SP LIBS Spectra by the PLSR Method

\begin{tabular}{|c|c|c|c|c|}
\hline \multirow{2}{*}{ Real Class } & \multirow{2}{*}{ Predicted Class } & \multicolumn{3}{|c|}{ Probability Distribution } \\
\hline & & PR & $\mathrm{PL}+\mathrm{PR}$ & $\mathrm{PL}+\mathrm{MAP}$ \\
\hline PR & PR & $* 0.761$ & 0.239 & 0 \\
\hline PR & PR & $* 0.958$ & 0.042 & 0 \\
\hline PR & PR & $* 0.934$ & 0 & 0.066 \\
\hline PR & PR & $* 0.574$ & 0.426 & 0 \\
\hline PR & PR & $* 0.837$ & 0 & 0.163 \\
\hline $\mathrm{PL}+\mathrm{PR}$ & $\mathrm{PL}+\mathrm{PR}$ & 0.021 & $* 0.979$ & 0 \\
\hline $\mathrm{PL}+\mathrm{PR}$ & $\mathrm{PL}+\mathrm{PR}$ & 0.007 & *0.993 & 0 \\
\hline $\mathrm{PL}+\mathrm{PR}$ & $\mathrm{PL}+\mathrm{PR}$ & 0.003 & $* 0.947$ & 0.05 \\
\hline $\mathrm{PL}+\mathrm{PR}$ & $P L+P R$ & 0 & $* 0.961$ & 0.039 \\
\hline $\mathrm{PL}+\mathrm{PR}$ & $\mathrm{PL}+\mathrm{PR}$ & 0.008 & $* 0.967$ & 0.024 \\
\hline $\mathrm{PL}+\mathrm{MAP}$ & $\mathrm{PL}+\mathrm{MAP}$ & 0 & 0 & $* 1$ \\
\hline $\mathrm{PL}+\mathrm{MAP}$ & $\mathrm{PL}+\mathrm{MAP}$ & 0 & 0.017 & *0.983 \\
\hline $\mathrm{PL}+\mathrm{MAP}$ & $\mathrm{PL}+\mathrm{MAP}$ & 0.004 & 0.009 & $* 0.987$ \\
\hline $\mathrm{PL}+\mathrm{MAP}$ & $\mathrm{PL}+\mathrm{MAP}$ & 0 & 0 & $* 1$ \\
\hline $\mathrm{PL}+\mathrm{MAP}$ & $\mathrm{PL}+\mathrm{MAP}$ & 0.011 & 0.097 & *0.893 \\
\hline
\end{tabular}

* Classification value for each sample.

In order to validate the PCA sample classification into three groups, the PLSR approach for classification via regression was applied. This method allowed us to evaluate the variation of response variables, i.e., the sample groups, by finding the best combination of prediction variables, i.e., of spectra points. The accuracy of the method was evaluated using the raw and normalized SP LIBS spectra of all samples examined to obtain the so-called PLSR confusion matrices. Apparently, the samples could be correctly classified along the principal diagonal of the matrix with error values of 0 , which confirmed that no samples were classified incorrectly, i.e., an accuracy of $100 \%$ was obtained. 
The probability distributions obtained by the PLSR classifier for the raw spectra are shown in Table 2. The "real class" of the samples is listed in first column, whereas the second column, i.e., the "predicted class", lists the samples as they are classified by the model. A fully consistent correspondence was found between the two columns, which confirmed the $100 \%$ accuracy of the prediction model. The other three columns list the numerical probability distribution of each individual sample in each group. As an example, in the first row of Table 2, the probability of the sample PR to be predicted by the PLSR classifier model as a real PR is $76.1 \%$, to belong to the PL + PR class is $23.9 \%$, and to the PL + MAP class is $0 \%$, i.e., the sample results classified correctly. The method was thus validated in terms of accuracy and precision.

Conclusions. Results of this study showed that both LIBS systems used, i.e., SP LIBS-CCD and SP and DP LIBS ICCD, associated with multivariate PCA and PLSR analyses were able to distinguish and classify with good accuracy the phosphate rocks and organomineral fertilizers examined. Further, the comparative examination of results obtained using the two LIBS systems and either PCA or PLSR approaches showed that it was possible to classify quickly and correctly phosphate rocks and organomineral fertilizers of different source and composition on the basis of raw LIBS spectra acquired using a spectral and temporal resolution compatible with a commercial portable LIBS-CCD system that potentially allows in situ measurements. Although LIBS still faces a number of challenges related to the secondary correlations on which it is based when combined with chemometric processing of data in real time, this technique has proved to represent a promising, novel, valuable, rapid, and relatively low-cost analytical tool for $\mathrm{P}$ fertilizer analysis featuring several advantages over current methodologies.

Acknowledgments. The authors acknowledge financial support from São Paulo Research Foundation (FAPESP) grant projects (2013/02165-7; 2013/07276-1) and scholarship (2012/24349-0), CNPq grant (2014/461743-0), and Embrapa. The authors are grateful to Paulo César Teixeira for ICP-OES analysis.

\section{REFERENCES}

1. R. W. Scholz, A. H. Roy, F. S. Brand, D. T. Hellums, and A. E. Ulrich, Sustainable Phosphorus Management: A Global Transdisciplinary Roadmap, Springer, Netherlands (2013).

2. D. W. Hahn and N. Omenetto, Appl. Spectrosc., 66, 347-419 (2012).

3. G. G. Arantes de Carvalho, J. Moros, D. Jr. Santos, F. J. Krug, and J. J. Laserna, Anal. Chim. Acta, 876, $26-38$ (2015).

4. V. S. Burakov, S. N. Raikov, N. V. Tarasenko, M. V. Belkov, and V. V. Kiris, J. Appl. Spectrosc., 77, 595-608 (2010).

5. M. A. Gondal and M. A. Dastageer, Springer Series in Opt. Sci., 182, 293-308 (2014).

6. J. Kaiser, K. Novotny, M. Z. Martin, A. Hrdlicka, R. Malina, M. Hartl, A. Vojtech, and R. Kizek, Surf. Sci. Rep., 67, 233-243 (2012).

7. G. Nicolodelli, G. S. Senesi, R. A. Romano, I. L. De Oliveira Perazzoli, and D. M. B. P. Milori, Spectrochim. Acta B, 111, 23-29 (2015).

8. D. Jr. Santos, L. C. Nunes, G. G. A. Carvalho, M. S. Gomes, P. F. Souza, F. O. Leme, L. G. C. Santos, and F. J. Krug, Spectrochim. Acta B, 71-72, 3-13 (2012).

9. G. S. Senesi, M. Dell'Aglio, A. De Giacomo, O. De Pascale, Z. A. Chami, T. M. Miano, and C. Zaccone, Clean — Soil, Air, Water, 42, 791-798 (2014).

10. W. Tawfik, W. A. Farooq, F. N. Al-Mutairi, and Z. A. Alahmed, Laser Eng., 32, 129-140 (2015).

11. K. Chen and J. Lu, QiangjiguangYuLizishu/High Power Laser and Particle Beams, 23, 293-297 (2011).

12. W. A. Farooq, F. N. Al-Mutairi, A. E. M. Khater, A. S. Al- Dwayyan, M. S. AlSalhi, and M. Atif, Opt. Spectrosc., 112, 874-880 (2012).

13. Y. Groisman and M. Gaft, Spectrochim. Acta B, 65, 744-749 (2010).

14. J. Li, S. Yao, J. Lu, J. Li, K. Chen, and M. Dong, J. Anal. At. Spectrom., 25, 1733-1738 (2010).

15. B. Marangoni, K. S. G. Silva, G. Nicolodelli, G. S. Senesi, J. S. Cabral, P. R. Villas-Boas, C. S. Silva, P. C. Teixeira, A. A. Nogueira, V. M. Benites, and D. M. B. P. Milori, Anal. Method., 8, 78-82 (2015).

16. L. C. Nunes, G. C. A. De Carvalho, D. Jr. Santos, and F. J. Krug, Spectrochim. Acta B, 97, 42-48 (2014).

17. S. M. Clegg, E. Sklute, M. D. Dyar, J. E. Barefield, and R. C. Wiens, Spectrochim. Acta B, 64, 79-88 (2009).

18. D. L. Death, A. P. Cunningham, and L. J. Pollard, Spectrochim. Acta B, 64, 1048-1058 (2009).

19. J. B. Sirven, B. Bousquet, L. Canioni, and L. Sarger, Anal. Chem., 78, 1462-1469 (2006).

20. S. Wold, M. Sjöström, and L. Eriksson, Chemometr. Intell. Lab., 58, 109-130 (2001).

21. R. L. Ott and M.T. Longnecker, A First Course in Statistical Methods, Duxbury Press, Belmont (2003). 